\title{
L1/Laminin Modulation of Growth Cone Response to EphB Triggers Growth Pauses and Regulates the Microtubule Destabilizing Protein SCG10
}

\author{
Leejee H. Suh, ${ }^{1 \star}$ Stephen F. Oster, ${ }^{1 \star}$ Sophia S. Soehrman, ${ }^{2}$ Gabriele Grenningloh, ${ }^{2}$ and David W. Sretavan ${ }^{1}$ \\ ${ }^{1}$ Departments of Ophthalmology and Physiology, University of California San Francisco, San Francisco, California 94143, and ${ }^{2}$ Institut de Biologie Cellulaire \\ et de Morphologie, University of Lausanne, 1005 Lausanne, Switzerland
}

\begin{abstract}
During development, EphB proteins serve as axon guidance molecules for retinal ganglion cell axon pathfinding toward the optic nerve head and in midbrain targets. To better understand the mechanisms by which EphB proteins influence retinal growth cone behavior, we investigated how axon responses to $\mathrm{EphB}$ were modulated by laminin and L1, two guidance molecules that retinal axons encounter during in vivo pathfinding. Unlike EphB stimulation in the presence of laminin, which triggers typical growth cone collapse, growth cones co-stimulated by L1 did not respond to EphB. Moreover, EphB exposure in the presence of both laminin and L1 resulted in a novel growth cone inhibition manifested as a pause in axon elongation with maintenance of normal growth cone morphology and filopodial activity. Pauses were not associated with loss of growth cone actin but were accompanied by a redistribution of the microtubule cytoskeleton with increased numbers of microtubules extending into filopodia and to the peripheral edge of the growth cone. This phenomenon was accompanied by reduced levels of the growth cone microtubule destabilizing protein SCG10. Antibody blockade of SCG10 function in growth cones resulted in both changes in microtubule distribution and pause responses mirroring those elicited by EphB in the presence of laminin and L1. These results demonstrate that retinal growth cone responsiveness to EphB is regulated by co-impinging signals from other axon guidance molecules. Furthermore, the results are consistent with EphB-mediated axon guidance mechanisms that involve the SCG10-mediated regulation of the growth cone microtubule cytoskeleton.
\end{abstract}

Key words: axon pathfinding; growth cones; cytoskeleton; guidance molecules; SCG10; microtubules; EphB; L1; laminin; retina; timelapse microscopy

\section{Introduction}

Interactions between EphB and B ephrin molecules mediate multiple developmental events, including cell migration, growth cone guidance, and dendritic development (Henkemeyer et al., 1996; Xu et al., 1999; Ethell et al., 2001; Lu et al., 2001). Mice with deletions of EphB2 and EphB3 genes exhibit retinal axon pathfinding errors in which dorsal retinal axons after reaching the immediate region of the optic disc bypass this exit point to grow inappropriately into the opposite side of the retina (Birgbauer et al., 2000). Because overall EphB protein levels are higher in ventral compared with dorsal retina (Birgbauer et al., 2000), and EphB extracellular domain proteins by themselves trigger growth cone collapse (Birgbauer et al., 2001), a model was proposed in which dorsal axons heading ventrally toward the optic disc re-

Received Sept. 23, 2003; revised Dec. 17, 2003; accepted Dec. 30, 2003.

This work was supported by National Institutes of Health and the That Man May See Foundation to D.S. and the National Science Foundation of Switzerland to G.G. (Grant 31-61600.00). We thank Andre Sobel for SCG10 antibodies, Louis Reichardt and Eric Birgbauer for helpful discussions, and Chris Severin, Anny Shai, and Evelyne Ruchti for technical help.

* L.H.S. and S.F.O. contributed equally to this work.

Correspondence should be addressed to David W. Sretavan, Departments of Ophthalmology and Physiology, University of California San Francisco, Box 0730, 10 Kirkham Street, San Francisco, CA 94143. E-mail: dws@itsa.ucsf.edu.

DOI:10.1523/JNEUROSCI.1670-03.2004

Copyright $\odot 2004$ Society for Neuroscience $\quad$ 0270-6474/04/241976-11\$15.00/0 spond to an increasing gradient of inhibitory EphB proteins to maintain the tight fasciculation necessary for axon accurate targeting of the optic disc.

EphB and B ephrin interactions in the visual system are highly regulated and context dependent in that signaling after ligandreceptor interactions can occur in either the forward or reverse direction and can also result in either attractive or repulsive growth cone responses (Birgbauer et al., 2000, 2001; Nakagawa et al., 2000; Hindges et al., 2002; Mann et al., 2002). Although retinal growth cones within the retina respond to EphB proteins as inhibitory guidance molecules (Birgbauer et al., 2000, 2001), retinal axons and growth cones in the optic tectum-superior colliculus either use $\mathrm{EphB}$ molecules as guidance receptors (Hindges et al., 2002) or respond to EphB molecules as a growthpromoting axon guidance molecule (Mann et al., 2002). The mechanisms that govern the ability of retinal growth cones to alter their responsiveness to $\mathrm{EphB}$ proteins as guidance molecules are unknown.

In the present study, we investigated how retinal growth cone responsiveness to EphB proteins may be regulated by concurrent stimulation by other axon guidance molecules. Growth cone response to specific axon guidance molecules can be modulated by co-impinging signals activated by a second guidance molecule (Hopker et al., 1999; Song and Poo, 1999; Castellani et al., 2000; 
Stein and Tessier-Lavigne, 2001). For example, although retinal axons typically grow toward a source of the chemoattractant netrin-1, retinal axons in the presence of laminin switch their response to netrin-1 from attraction to repulsion (Hopker et al., 1999). Similarly, L1, a cell adhesion molecule of the immunoglobulin family, has been shown to cause cortical axons to switch their response to Sema3A from repulsion to attraction (Castellani et al., 2000). These findings suggest that retinal growth cone responses to EphB may be governed by co-impinging signals provided by other relevant axon guidance molecules present in the developing visual pathways.

Two guidance molecules well positioned in vivo to influence EphB function in the retina are laminin and L1. Laminins are localized along the optic nerve, along the optic tract (Liesi and Silver, 1988; Morissette and Carbonetto, 1995; Hall et al., 1997), and in the optic disc region (Hopker et al., 1999). L1 is present on retinal axons (Bartsch et al., 1989; Hankin and Lagenaur, 1994; Lyckman et al., 2000), and L1 homophilic interactions are thought to be responsible for maintaining retinal axon fasciculation within the visual pathways, suggesting that many retinal axon pathfinding events likely occur in the presence of L1 signaling.

In a previous study (Birgbauer et al., 2001), the inhibitory effect of EphB proteins on retinal axons was demonstrated in the presence of laminin. EphB, when paired with laminin, triggered growth cone collapse, a characteristic response to inhibitory axon guidance molecules that involves Rho GTPase activity and growth cone actin disassembly (Luo, 2000). Although axon pathfinding and elongation must also involve precise control of the growth cone microtubule cytoskeleton, it is not clear how inhibitory signals such as those triggered by EphB are conveyed to microtubules. Although mechanisms involving cross talk between actin and microtubules (Krendel et al., 2002; Zhou et al., 2002) or actin-microtubule linker proteins (Lee and Kolodziej, 2002) may play a role, the possibility that inhibitory guidance molecules are capable of exerting an influence on growth cone microtubules independent of actin-mediated collapse has not been explored.

In this study, we analyzed retinal axon response to EphB in the presence of L1, or the combination of L1 and laminin, and compared the results with the previously characterized response to EphB in the presence of laminin (Birgbauer et al., 2001). In keeping with the methods used in Birgbauer et al. (2001), we began by recording the response of retinal axons and growth cones to guidance molecules delivered by micropipettes. In addition, we also examined axon and growth cone responses to pairings of guidance molecules immobilized to the substratum or applied by bath application. The results showed that retinal growth cones do not respond to EphB in the presence of L1. Furthermore, the combination of L1 and laminin signaling unmasked a form of EphBactivated growth cone inhibitory pause distinct from actinmediated collapse. Growth cone pauses were characterized by altered growth cone microtubule distribution and appeared to involve changes in the levels of SCG10 protein, a growth cone regulator of microtubule assembly.

\section{Materials and Methods}

Animals and tissues. Gestational day 14 mouse embryos were obtained from timed pregnant C57BL/6 mice anesthetized using intraperitoneal injections of sodium pentobarbital. Dorsal or ventral retinal tissue was dissected from embryos and used immediately for explant cultures. The use of animals in this study conformed to the University of California institutional guidelines.
Recombinant proteins. Human L1 cDNA encoding amino acids 1-1120 was cloned into pEX.Fc in-frame with human IgG-Fc $\gamma$ domain. Supernatant was collected from transfected cells, and L1-Fc protein was isolated by protein A chromatography. Anti-Fc immunoblot and silver staining revealed a single major band of $200 \mathrm{kDa}$ (data not shown). Coverslip dishes were coated with anti-human $\mathrm{Fc}(10 \mu \mathrm{g} / \mathrm{ml})$ followed by L1-Fc $(5 \mu \mathrm{g} / \mathrm{ml})$ to form an L1 substratum. L1-Fc $(5 \mu \mathrm{g} / \mathrm{ml})$ combined with laminin ( $5 \mu \mathrm{g} / \mathrm{ml}$; Invitrogen, Gaithersburg, MD) was used as mixed substratum. Human L1 cDNA was also expressed fused to a mychistidine tag and used as a retinal explant substratum in experiments to demonstrate EphB-Fc binding (see below).

Growth cone assays and time-lapse microscopy. F12/N2 medium containing EphB2-Fc or Fc (50 $\mu \mathrm{g} / \mathrm{ml})$, IKVAV $(50 \mu \mathrm{g} / \mathrm{ml}$; American Peptide), YIGSR (50 $\mu \mathrm{g} / \mathrm{ml}$; Sigma, St. Louis, MO), BSA (0.1\%), and fluorescein $(25 \mu \mathrm{g} / \mu \mathrm{l})$ was used for pipette delivery. In bath application, final concentrations were EphB2-Fc $(2 \mu \mathrm{g} / \mathrm{ml})$, IKVAV $(2 \mu \mathrm{g} / \mathrm{ml})$, and YIGSR $(2 \mu \mathrm{g} / \mathrm{ml})$. A limited number of experiments included the addition of anti-Fc antibodies to further oligomerize EphB2-Fc molecules. No qualitative differences were observed, and the bulk of experiments were performed using EphB-Fc dimers alone. Only results from experiments using EphB-Fc alone are reported. The growth rate of axons was determined by recording the distance traveled in the period $30 \mathrm{~min}$ before reagent application to arrive at an hourly "before" growth rate. Similarly, the distance traveled in the period 60-90 min after reagent application was used to arrive at an hourly "after" growth rate. Filopodial activity in paused growth cones was considered to be lost if no filopodia were observed to move over two consecutive time-lapse images (1 min apart) and there was no appearance of new filopodia.

Antibodies and immunohistochemistry. Tyrosinated microtubules were visualized using rat monoclonal antibody (mAb) YL1/2 at $0.5 \mu \mathrm{g} / \mathrm{ml}$ (Chemicon, Temecula, CA). Tyrosinated and non-tyrosinated microtubules were visualized using mouse mAb TUB 2.1 at $0.5 \mu \mathrm{g} / \mathrm{ml}$ (Sigma). SCG10 was specifically visualized using a purified anti-recombinant SCG10 antibody (Antonsson et al., 1998), and an antibody made against the SCG10 C-terminal peptide (Ozon et al., 1997). A nonpurified antiSCG10 antiserum was used to detect both SCG10 and stathmin in immunoblots for the characterization of the specificity of anti-SCG10 phospho-antibodies (see below). Nck $\beta$ antibody (Upstate Biotechnology) was used at $10 \mu \mathrm{g} / \mathrm{ml}$. Microtubule-associated protein 1B (MAP1B) was detected using mouse mAb AA6 at $0.5 \mu \mathrm{g} / \mathrm{ml}$ (Sigma-Aldrich).

Growth cones extending on L1 and exposed to bath-applied EphB2 and laminin peptides for 5-60 min were fixed for $15 \mathrm{~min}$ using $4 \%$ paraformaldehyde with $0.1 \%$ glutaraldehyde for microtubule immunostaining. Growth cones used for the localization of $\mathrm{Nck} \beta$ or colocalization of SCG10, MAP1B with microtubules, were fixed with $4 \%$ paraformaldehyde for $15 \mathrm{~min}$. After incubation in 10\% blocking serum and $0.1 \%$ Triton X-100 for $30 \mathrm{~min}$, immunostaining was performed with primary antibody in $0.1 \%$ BSA, $0.1 \%$ Triton $\mathrm{X}-100$, and $1 \%$ blocking serum for $2-3 \mathrm{hr}$ at $25^{\circ} \mathrm{C}$ followed by appropriate labeled secondary antibodies.

EphB-Fc binding on axons. EphB-Fc binding on axons extending on L1 substratum was performed as described previously (Birgbauer et al., 2001). Retinal explants were grown on recombinant L1 fused to mychistidine. After BSA $(1 \mathrm{mg} / \mathrm{ml})$ blockade for $30 \mathrm{~min}$ at $37^{\circ} \mathrm{C}$, retinal explants and axons were washed and incubated with EphB2-Fc $(10 \mu \mathrm{g} /$ $\mathrm{ml})$ or Fc control protein in Ringer's solution containing BSA $(1 \mathrm{mg} / \mathrm{ml})$ for $60 \mathrm{~min}$ at $4^{\circ} \mathrm{C}$. Explants were then fixed with $2 \%$ paraformaldehyde and stained with Cy3-conjugated anti-human IgG (Fc $\gamma$ specific) antibody to visualize EphB2-Fc binding. The growth cone responses to EphB described in this study were observed when using either L1-Fc or L1myc-histidine recombinant proteins as substratum.

Quantitation of SCG10 and MAP1B immunoreactivity in growth cones. Growth cones extending on L1 were exposed to bath-applied EphB2 and laminin peptides for $5 \mathrm{~min}$, fixed, and stained using purified antirecombinant SCG10 (Antonsson et al., 1998), anti-SCG10 C-terminal peptide (Ozon et al., 1997), or mouse mAb AA6 against MAP1B (Sigma-Aldrich).

Anti-SCG10 and MAP1B immunoreactivity were detected using appropriate Cy3-labeled secondary antibodies and digital fluorescent im- 
ages captured using a cooled CCD camera (PXL, Photometrics) and Deltavision imaging software (Applied Precision Inc.). Camera exposure time was identical for all growth cones in experimental and control groups. For each growth cone, the boundary of the growth cone including filopodia, lamellapodia, and the body of the growth cone was traced, and the area of the growth cone was determined. The total fluorescence signal above background within each growth cone (derived from SCG10 or MAP1B immunoreactivity) was then obtained. A two-sample Wilcoxon test was used to compare the distribution of pixel values in the population of growth cones on L1 with that in growth cones on L1 exposed to EphB2 and laminin peptides.

SCG10 phospho-antibodies. Rabbit polyclonal anti-peptide antibodies against SCG10 phosphorylation sites Ser 50, 62, and 73 were generated at Eurogentec (Seraing, Belgium) using the synthetic peptides CEVKQINKRApSGQA, KPPpSPISEAPRTC, and RTLApSPKKKDLC conjugated to KLH. Affinity purification was performed against the corresponding phosphorylated peptide and then against the nonphosphorylated peptide to eliminate cross-reacting antibodies. The specificity of the antibodies was verified by both immunofluorescence and Western blot analysis. Anti-phosphopeptide antibodies stained COS-7 cells transfected with wild-type SCG10 (which is known to be phosphorylated in COS cells) but not COS-7 cells transfected with either stathmin or phosphorylation-site mutant forms of SCG10 (Antonsson et al., 1998). In immunoblots, there was no cross-reactivity with the recombinant protein SCG10 produced in Escherichia coli (N-terminally truncated form) (Antonsson et al., 1997) or with stathmin expressed in COS-7 cells or purified from E. coli or baculovirus (Antonsson et al., 2001). SCG10 phospho-antibodies were used at 1:50 for immunocytochemistry and at 1:2500 for Western blots.

Anti-SCG10 mAb effects on microtubule assembly. The effects of SCG10 and anti-SCG10 mAb on microtubule formation were measured using an in vitro assay of microtubule assembly (Riederer et al., 1997). Hybridoma supernatant $(150 \mathrm{ml})$ was purified on HiTrap Protein G column (Amersham Biosciences, Arlington Heights, IL), desalted on a Hitrap desalting column (Amersham Biosciences), and concentrated using CentriconYM-30 (Millipore, Bedford, MA) according to the manufacturer's protocols. Mixed tubulin (tubulin with microtubule-associated proteins; $1.8 \mathrm{mg} / \mathrm{ml}$ ) was incubated at $4^{\circ} \mathrm{C}$ in PIPES-EGTA- $\mathrm{MgSO}_{4}$ buffer containing $1 \mathrm{mM}$ GTP either alone or in the presence of $6 \mu \mathrm{M}$ SCG10. To test the ability of anti-SCG10 mAb to block SCG10 function, $6 \mu \mathrm{M}$ SCG10 was preincubated for 45 min with $6 \mu \mathrm{M}$ anti-SCG10 mAb before adding to the tubulin buffer mix. As control, $6 \mu \mathrm{M}$ SCG10 was preincubated for $45 \mathrm{~min}$ with $6 \mu \mathrm{m}$ mouse IgG and added to the tubulin buffer mix. Polymerization was induced by raising the temperature to $37^{\circ} \mathrm{C}$ (time 0 ) and monitored by measuring the absorbance at $350 \mathrm{~nm}$ over a period of $30 \mathrm{~min}$ in a Uvikon XS spectrophotometer (Bio-Tek instruments).

Perturbation of SCG10 function. SCG10 function-blocking mAb (10 $\mu \mathrm{g})$ and $\mathrm{Cy} 2$ donkey anti-rabbit $\mathrm{Ab}(3.75 \mu \mathrm{g}$; Jackson ImmunoResearch, West Grove, PA) were added to $3 \mu \mathrm{l}$ of a cationic lipid formulation (Zelphati et al., 2001), (Bioporter, Gene Therapy Systems) and reconstituted in $100 \mu \mathrm{l}$ of HEPES-buffered saline. After mixing, $20 \mu \mathrm{l}$ of AbBioporter mix was added to the central well of a coverslip dish containing retinal explants and $200 \mu \mathrm{l}$ of $\mathrm{F} 12 / \mathrm{N} 2$ medium at $37^{\circ} \mathrm{C}, 5 \% \mathrm{CO}_{2}$ for 30 min. F12/N2 medium was then added to achieve a $2 \mathrm{ml}$ volume for an additional 60 min before commencing time-lapse recordings of growth cone behaviors. Growth cones were examined for Cy2 fluorescence to confirm antibody loading. In control experiments, SCG10 mAb was substituted with Cy2 donkey anti-rabbit Ab, SCG10 polyclonal antibody, or rat anti-tubulin $\mathrm{mAb}$ (Chemicon) conjugated with Alexafluor 488 (Molecular Probes, Eugene, OR). After time-lapse recording, growth cones treated with SCG10 function-blocking $\mathrm{mAb}$ were fixed and stained with rat $\mathrm{mAb} Y L 1 / 2(0.5 \mu \mathrm{g} / \mathrm{ml}$; Chemicon $)$ as described above to visualize the distribution of tyrosinated microtubules.

\section{Results}

Growth cones on L1 substratum do not respond to EphB

Embryonic mouse retinal axons from dorsal retina were grown overnight on a substratum of L1-Fc recombinant fusion protein,
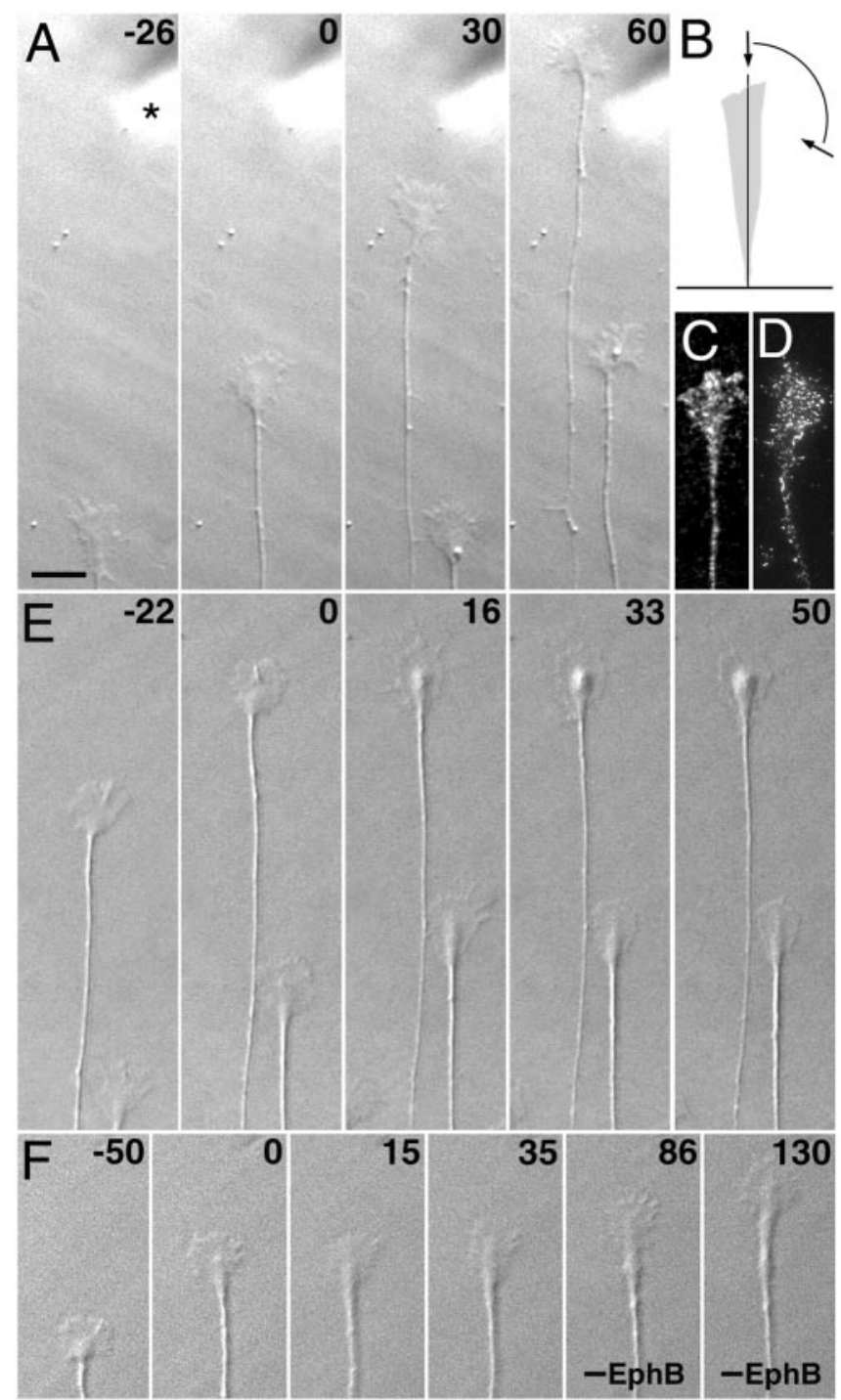

Figure 1. Pause behavior in growth cones. $A$, Time-lapse sequence of embryonic mouse retinal growth cones extending on L1 substratum and their response to EphB-Fc. Time elapsed (in minutes) is shown in the top right of panels. " 0 " represents onset of EphB-Fc application via micropipette (asterisk). EphB did not affect axon growth. Scale bar, $10 \mu \mathrm{m}$. B, Trajectories of axons on L1-Fc after EphB-Fcexposure. The arrows bracket the angles of pipette placement with respect to orientation of axons tested. The area containing all axon trajectories is shaded gray. EphB-Fc exposure did not produce a growth bias toward or away from the pipette. C, EphB-FC binding on retinal growth cone on L1. D, Anti-Nck $\beta$ immunostaining of retinal growth cone on L1. E, Time-lapse sequence of growth cones on L1-Fc substratum responding to pipette application of EphB-Fc and laminin peptides at $t=0$. Growth cones showed a pause behavior characterized by no forward advance but continued filopodia and lamellapodia activity. F, Timelapse sequence of a paused growth cone resuming forward elongation after reagent removal at $60 \mathrm{~min}$. [The growth cone pauses with continued filopodial activity described in this study were distinct from a previously reported growth cone freezing phenomenon (Birgbauer et al., 2001). Growth cone freezing was characterized by total loss of filopodial movements and occurred at low frequency after retinal growth cones on laminin were exposed to either EphB or control Fc proteins.]

and their response to EphB molecules delivered by micropipette was recorded using time-lapse microscopy. Unlike retinal growth cones on laminin, which collapsed in response to EphB1, -2 , or -3 (Birgbauer et al., 2001), growth cones on L1 did not collapse and instead steadily advanced, ignoring the application of these guidance molecules (Fig. 1A, Table 1). (Also see http://www.ucsfeye. net/sretmovies/sretmovies.htm for time-lapse movies of growth 
Table 1. E14 retinal growth cone response to combinations of $L 1, L N$, and EphB proteins

\begin{tabular}{|c|c|c|c|c|c|c|}
\hline \multirow[b]{2}{*}{ Substratum } & \multirow[b]{2}{*}{ Reagents applied } & \multirow[b]{2}{*}{ Number tested } & \multirow[b]{2}{*}{$\%$ Responding } & \multicolumn{3}{|c|}{ Number of axons exhibiting } \\
\hline & & & & Collapse & Pause & Other \\
\hline \multirow[t]{4}{*}{ L1 } & EphB1 & 49 & 10 & 1 & 0 & 4 \\
\hline & EphB2 & 47 & 11 & 2 & 0 & 3 \\
\hline & EphB3 & 40 & 20 & 2 & 0 & 6 \\
\hline & $\mathrm{Fc}$ & 42 & 16 & 2 & 0 & 5 \\
\hline \multirow[t]{2}{*}{ L1 and laminin } & EphB2 & 67 & $69^{*}$ & 10 & 17 & 19 \\
\hline & EphB2 (inactivated) & 32 & 28 & 3 & 0 & 6 \\
\hline \multirow[t]{3}{*}{ L1 } & EphB2 and LN pep & 83 & $77^{*}$ & 11 & 50 & 3 \\
\hline & EphB2 (inactivated) and LN pep & 31 & 23 & 2 & 0 & 5 \\
\hline & Fc and LN pep & 33 & 6 & 1 & 0 & 1 \\
\hline \multirow[t]{2}{*}{ L1 } & EphB2 and LN pep (bath applied) & 32 & $75^{\dagger}$ & 1 & 18 & 5 \\
\hline & Fc and LN pep (bath applied) & 30 & 20 & 2 & 0 & 4 \\
\hline
\end{tabular}

Asterisks mark response rates that were significantly different from the inactivated EphB controls within that experimental group $(p<0.001 ; t$ test). The dagger indicates a significant difference from the $\mathrm{Fc}$ controls ( $p<0.001 ; t$ test). The vast majority of responses in the "other" category represented a decrease in speed. A significant decrease in speed was defined as a reduction in speed to $<60 \%$ of baseline, and by $>25 \mu \mathrm{m} / \mathrm{hr}$. Growth cone turning was a rare occurrence. LN pep, Laminin peptides IKVAV and YIGSR.
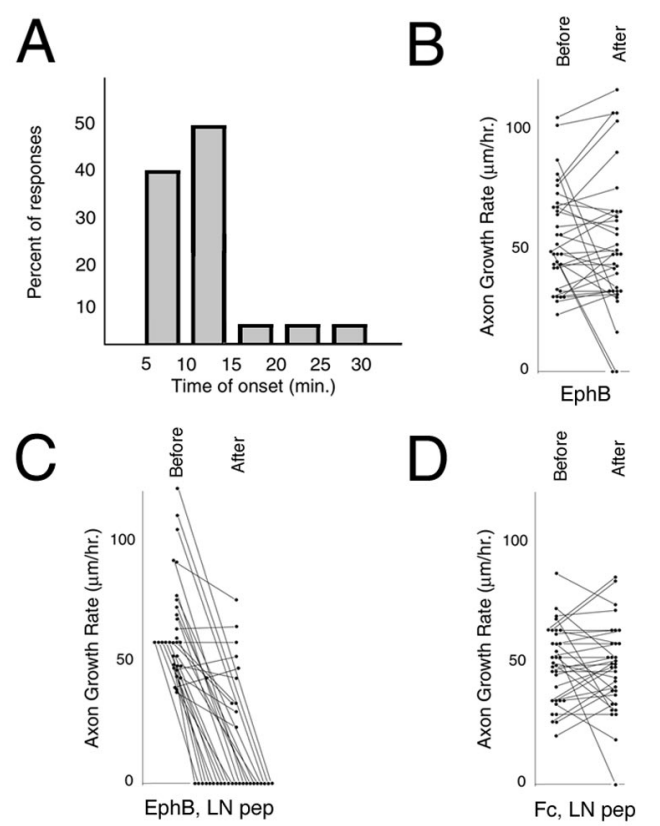

Figure 2. Characterization of growth cone responses. $A$, Graph showing the time interval (in minutes) between the application of EphB proteins and onset of pause response in retinal growth cones $(n=85)$. The percentage of responses that occurred within each 5 min interval between 0 and $30 \mathrm{~min}$ is plotted. The mean onset time for retinal growth cones extending on L1 and laminin and exposed to EphB proteins ( $12 \pm 6 \mathrm{~min} ; n=17)$ was not significantly different from that for growth cones on $L 1$ exposed to EphB and laminin peptides by micropipette (11 \pm $6 \mathrm{~min} ; n=50$ ) or for growth cones on L1 exposed to EphB and laminin peptides by bath application (10 \pm 7 min; $n=18$ ). $B$, Graph showing growth rates of axons extending on L1 before and after exposure to EphB. A solid line links the growth rates for each axon before and after reagent exposure. C, Graph showing growth rates of axons extending on L1 before and after exposure to EphB and laminin peptides. A solid line links the growth rates for each axon before and after reagent exposure. Growth rates of zero after reagent exposure represent paused growth cones. Axons extending on L1 with growth rates of $40 \mu \mathrm{m} / \mathrm{hr}$, as well as those of $>100 \mu \mathrm{m} / \mathrm{hr}$, exhibited pauses after exposure to EphB and laminin peptides. D, Graph showing growth rates of axons extending on $\mathrm{L} 1$ before and after exposure to $\mathrm{Fc}$ and laminin peptides.

cone responses described in this study.) Axon trajectories after EphB exposure were not biased toward or away from the delivery micropipette (Fig. $1 B$ ) and the mean $( \pm$ SD) axon growth speed before and after EphB application also did not vary (before: $56 \pm$ $20 \mu \mathrm{m} / \mathrm{hr}$; after: $51 \pm 27 \mu \mathrm{m} / \mathrm{hr} ; n=43 ; p=0.33$ ) (Fig. $2 B$ ). Retinal growth cones on L1 exhibited EphB protein binding (Fig. $1 C$ ) in a pattern similar to that of EphB protein binding on retinal growth cones extending on laminin (Birgbauer et al., 2001). No specific binding was observed using Fc control protein (data not shown). In addition, retinal growth cones on L1 also expressed Nck $\beta$ (Fig. 1D), a signaling intermediate involved in Ephrin B reverse signaling after EphB binding (Cowan and Henkemeyer, 2001). Together these results indicated that EphB inhibition of retinal growth cones was differentially affected by L1 signaling compared with laminin. This difference also did not appear to be caused simply by abnormal EphB protein binding or the lack of $\mathrm{Nck} \beta$ in retinal growth cones on $\mathrm{L} 1$.

\section{EphB, laminin, and L1 trigger growth cone pauses}

To examine whether signals generated by L1 completely blocked the ability of EphB to inhibit retinal growth cones, we reintroduced laminin, noting that previous studies of EphB function in axon pathfinding (Birgbauer et al., 2001) and cell migration (Lu et al., 2001) were performed in the presence of laminin. Retinal growth cones recovered their responsiveness to EphB2 when exposed to the combination of L1, laminin, and EphB2 (Fig. 1E, Table 1). This recovery was observed under three different experimental conditions: (1) axons extending on a mixed substratum of L1 and laminin and then exposed to EphB2 delivered via micropipette, (2) axons grown on L1 and exposed to both EphB2 and laminin peptides (YIGSR, IKVAV) (Hopker et al., 1999) by micropipette, and (3) axons on L1 exposed to bath application of EphB2 and laminin peptides.

Growth cone inhibition triggered by this L1, laminin, and EphB combination was notably different, however, in that it did not lead to morphological collapse. Instead, growth cones exhibited a specific pause behavior during which they ceased forward elongation while maintaining filopodial activity and a fan-like morphology (Figs. 1 E,F, 3B-E). Paused growth cones were indistinguishable from normal growth cones simply by static morphological analysis and required observation using time-lapse microscopy. Removal of EphB exposure led to resumption of axon elongation (Fig. $1 \mathrm{~F}$ ), indicating the viability of growth cones during pauses and the reversibility of this response. Pauses occurred as quickly as within $5 \mathrm{~min}$ of reagent application (Fig. $2 \mathrm{~A}$ ) and had an average time of onset of $11 \mathrm{~min}(n=85$; all three experimental conditions described above). The occurrence of pausing was not related to the speed of axon growth, because slower growth cones extending at rates of $40 \mu \mathrm{m} / \mathrm{hr}$ as well as faster growth cones extending at $>100 \mu \mathrm{m} / \mathrm{hr}$ both exhibited pauses in response to L1, laminin, and $\mathrm{EphB}$ proteins (Fig. $2 \mathrm{~B}$ ). The mean \pm SD growth rate of axons on L1 before the addition of EphB and laminin peptides was $57 \pm 19 \mu \mathrm{m} / \mathrm{hr}$ compared with 

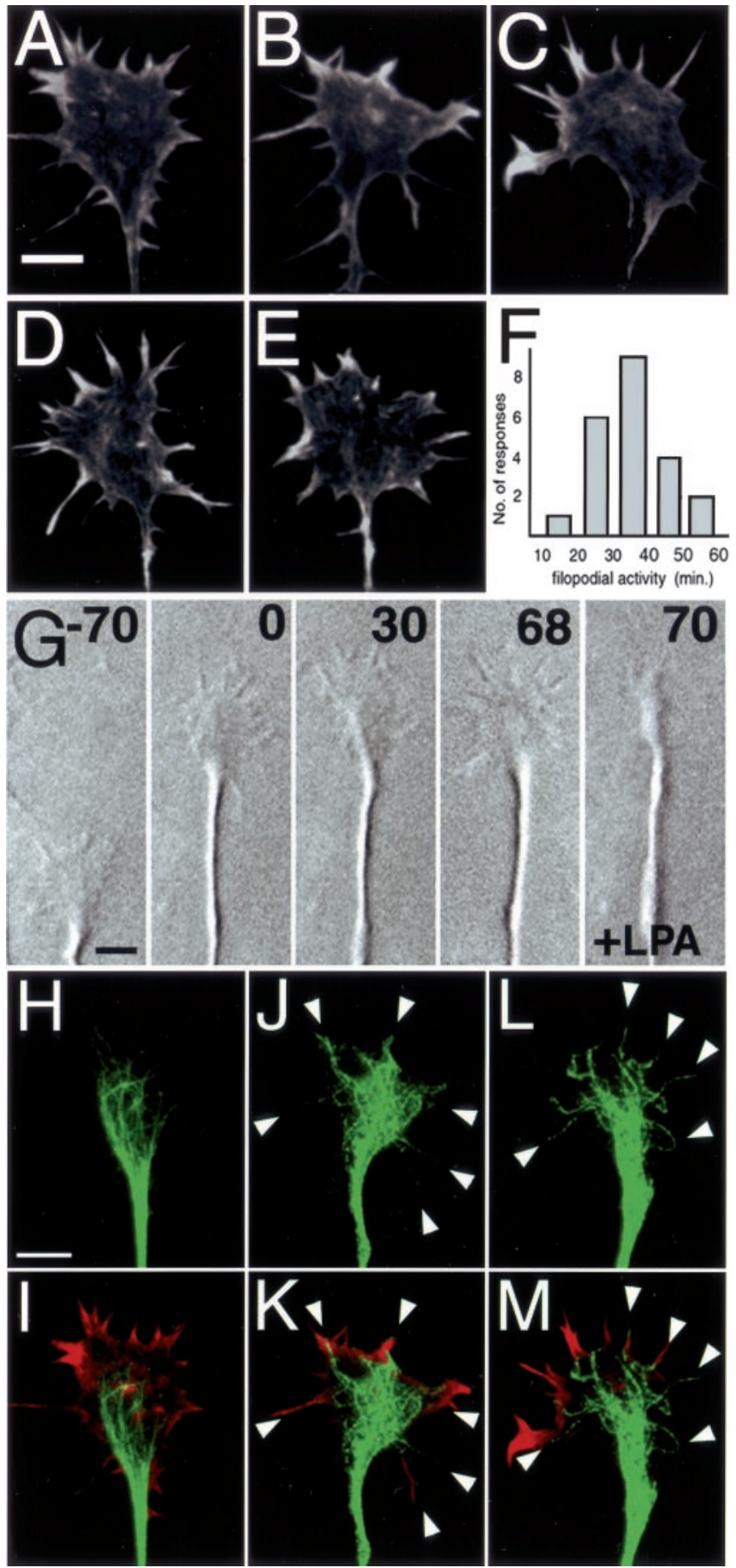

Figure 3. Distribution of actin and microtubules, filopodial activity, and LPA-induced collapse in paused growth cones. $A$, Texas Red phalloidin staining of actin distribution in a normal growth cone on L1. Scale bars: $A-E, 5 \mu \mathrm{m}$. $B-E$, Actin was present at the periphery and in filopodia of growth cones on $\mathrm{L} 1$ after EphB and laminin peptide exposure for $10 \mathrm{~min}(B, C)$ and 30 $\min (D, E) . F$, The duration of filopodial activity in paused growth cones. Between 10 and $60 \mathrm{~min}$, the number of growth cones that ceased filopodial activity in each 10 min interval is plotted. Growth cones typically did not collapse even after cessation of filopodial activity. G, Time-lapse sequence of LPA treatment on a paused growth cone. LPA was applied at $65 \mathrm{~min}$ and triggered growth cone collapse within $5 \mathrm{~min}$. Scale bar, $5 \mu \mathrm{m}$. $\mathrm{H}$, Distribution of tyrosinated microtubules (green) in a normal growth cone on L1. I, Microtubules (green) and actin (red) in the same growth cone in $L$ showing the segregation of microtubules into the central part of the growth cone and actin into the growth cone periphery and in filopodia. J, Microtubules in a growth cone on L1 after exposure to EphB-Fc and laminin peptides. Note long curved microtubules (arrowheads) that extended into the periphery and filopodia. $K$, Colocalization of actin and microtubules in the growth cone shown in J. L, Microtubules in a second growth cone on L1 after
$8 \pm 21 \mu \mathrm{m} / \mathrm{hr}$ after reagent exposure $(n=38 ; p<0.001)$. Growth cone pauses were absent when Fc fragment was substituted for EphB-Fc (mean growth rate \pm SD before application was $51 \pm 15$ $\mu \mathrm{m} / \mathrm{hr}$; after application it was $50 \pm 13 \mu \mathrm{m} / \mathrm{hr} ; n=32 ; p=0.77$ ) (Fig. $2 B$, Table 1). Pauses were also absent when EphB-Fc was heat denatured (Table 1), indicating the requirement for functional EphB in this response. Growth cones of axons originating from ventral retina and extending on L1 did not respond to application of EphB-Fc protein alone or EphB-Fc combined with laminin peptides.

\section{Actin localization and function during pauses}

Three lines of evidence showed that growth cone pauses resulted from mechanisms distinct from those involved in actin-mediated collapse. First, unlike actin disassembly seen in growth cone collapse, actin distribution in paused growth cones up to $60 \mathrm{~min}$ after reagent exposure (detected using Texas Red phalloidin) was unaffected and remained concentrated in filopodia (Fig. 3A-E). Second, filopodial activity was maintained for an average of 30-40 min after pausing, and some growth cones demonstrated activity for $>60 \mathrm{~min}$ (Fig. $3 F$ ). Last, paused growth cones could be collapsed by addition of lysophosphatidic acid (LPA) (Fig. $3 G$ ), a reagent known to act through Rho GTPases to cause actinmediated growth cone collapse (Kozma et al., 1997; Kranenburg et al., 1999). Thus, growth cone pauses triggered by L1, laminin, and EphB can be separated experimentally from actin-mediated collapse. Furthermore, although paused growth cones were capable of actin-mediated collapse, this behavior was not activated in growth cones after EphB exposure in the presence of L1 and laminin.

\section{Altered microtubule organization in paused growth cones}

In contrast to actin, microtubules in paused growth cones were abnormally organized. In untreated growth cones on L1, tyrosinated microtubules, which represent the dynamic pool of microtubules in growth cones (Suter and Forscher, 2000), were characteristically found as a fan-shaped array in the central domain (Fig. $3 H$ ). In embryonic mouse retinal growth cones on L1, individual microtubules, with occasional exceptions, generally do not extend into the actin-rich peripheral regions of the growth cone (Fig. 3I, Table 2). This segregation of actin and microtubule domains is a well known feature of active growth cones (Forscher and Smith, 1988; Suter and Forscher, 2000). In growth cones exposed to the L1, laminin, and EphB combination and examined for microtubule distribution $(n=146)$, an enlarged microtubule array was seen after 5-10 min characterized by the presence in increased numbers of growth cones of long curved microtubules that extended into the growth cone periphery and even into individual filopodia (Fig. $3 J-M$, arrows, Table 2). Similar findings were obtained using an antibody against both tyrosinated and non-tyrosinated microtubules (data not shown). (The growth cones in Fig. $3 H-M$ are the same as those shown in Fig. 3A-C.)

A possible mechanism underlying these microtubule changes is a perturbation of microtubule distribution caused by a disruption in the balance of opposing microtubule stabilizing and de-

exposure to EphB-Fc and laminin peptides. Long curved microtubules (arrowheads) were present and extended into the periphery and some filopodia. $M$, Colocalization of actin and microtubules in the growth cone shown in $L$. Scale bars: $H-M, 5 \mu \mathrm{m}$. The actin distribution in the growth cones shown in $H, J$, and $L$ is shown in $A-C$. 
Table 2. Microtubule changes in L1, laminin, and EphB-treated growth cones

\begin{tabular}{lclll}
\hline Growth cones exposed to & Number & \% with long curved microtubules* & \% with microtubules in filopodia* & Number of microtubules in filopodia (mean) $^{\dagger}$ \\
\hline L1 & 72 & 18 & 13 & $0.3 \pm 0.6$ \\
L1, laminin (or LN pep), and EphB & 146 & 75 & 68 & $3.1 \pm 2.7$ \\
\hline
\end{tabular}

All three parameters of microtubule organization in growth cones on $\mathrm{L} 1$ compared with growth cones on $\mathrm{L} 1$, laminin (or $\mathrm{LN}$ pep), and EphB were significantly different $\left(p<0.001\right.$; ${ }^{*}{ }^{2}$ test; ${ }^{\dagger} t$ test)

stabilizing forces in growth cones (Suter and Forscher, 2000). Pharmacological agents that alter microtubule dynamics and increase microtubule stability are known to inhibit axon elongation and pathfinding (Tanaka et al., 1995; Rochlin et al., 1996; Challacombe et al., 1997; Gallo, 1998). This disruption of axon growth (Tanaka et al., 1995; Gallo 1998) is remarkably similar to the growth cone pauses described in the present study in response to axon guidance molecules. It is also seen after pharmacological alteration of microtubules in embryonic mouse retinal growth cones on L1 (S. F. Oster and D. W. Sretavan, unpublished observations).

\section{Changes in microtubule destabilizing protein SCG10}

Growth cone microtubule regulators include stabilizers such as MAP1B (Gordon-Weeks and Fischer, 2000) and destabilizers such as SCG10 and other stathmin family members (Ozon et al., 1998). SCG10 mRNA is highly expressed in embryonic retinal ganglion cells (Ozon et al., 1998; Nakazawa et al., 2000), and like stathmin (Walczak, 2000; Cassimeris, 2002), SCG10 inhibits microtubule dynamics and assembly in vitro (Riederer et al., 1997). SCG10 function in transfected cells is reduced by phosphorylation of serine residues (Antonsson et al., 1998), and in vivo, SCG10 expression in olfactory axons is downregulated after innervation of target glomeruli (Pellier-Monnin et al., 2001).

To investigate whether the pause behavior involved changes in microtubule regulators, we examined both microtubule stabilizers and destabilizers in growth cones extending on L1 and exposed to EphB and laminin. SCG10 in retinal growth cones was examined using two anti-SCG10 polyclonal antibodies against either recombinant SCG10 (Antonsson et al., 1998) or SCG10 C-terminal peptide (Ozon et al., 1997). Phosphorylated SCG10 was detected using three polyclonal antibodies generated against SCG10 phosphopeptides and specifically recognizing phosphorylation at serine 50,62, and 73, respectively (Fig. 4). In normal retinal axons extending on L1 $(n=47)$, SCG10 was present in the axon shaft and in a punctate-aggregate pattern in the central domain of growth cones (Fig. $5 A$, top), corresponding to the zone occupied by microtubules (Fig. $5 A$, bottom). This SCG10 was not phosphorylated at serines 62 (Fig. 5B), 50, or 72 (data not shown), indicating that full SCG10 function may normally be required in active retinal growth cones. No increase in phosphorylation was detected in growth cones after exposure to the L1, laminin, and EphB combination $(n=101)$ (Fig. $5 C$ ), indicating that SCG10 phosphorylation likely did not play a role in growth cone pauses.

Analysis of overall SCG10 levels, however, showed that growth cones treated with L1, laminin, and EphB often showed a reduction or even an absence of total SCG10 (Fig. 5D, E, top panels). Anti-SCG10 fluorescence intensity was measured in normal growth cones extending on $\mathrm{L} 1$ and in growth cones extending on $\mathrm{L} 1$ treated by bath application of EphB and laminin peptides for $5 \mathrm{~min}$ and then fixed. (According to the response frequency and response type data in Table $1, \sim 60 \%$ of growth cones were predicted to show a pause response.) The mean fluorescence value in normal growth cones (Fig. 6A) was $1778 \pm 920(n=$ 136), compared with that in treated growth cones (Fig. $6 B$ ) of

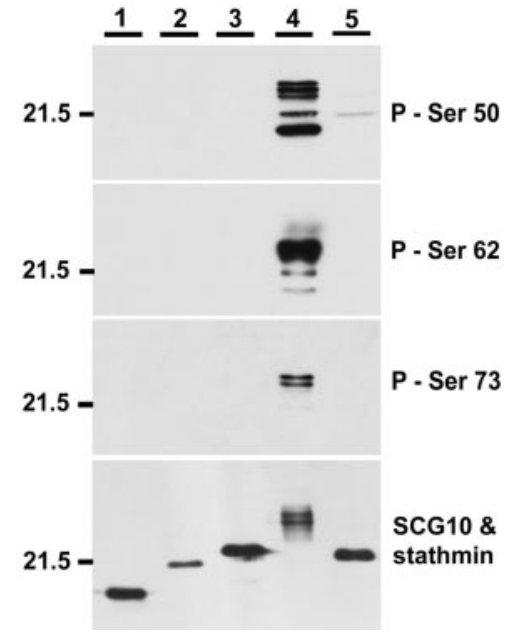

Figure 4. Immunoblot analysis of SCG10 phospho-antibodies on 14\% SDS-PAGE. Protein loading: Lane 1, Unphosphorylated SCG10 produced in E. coli (35 ng); lane 2, stathmin produced in E. coli; lane 3, stathmin produced in baculovirus; lane 4, phosphorylated SCG10 expressed in COS-7 cells $(5 \mu \mathrm{g})$; lane 5, protein extract from COS-7 cells $(5 \mu \mathrm{g})$. Phosphorylated SCG10 produced in COS-7 cells (lane 4) is recognized by anti-phosphoserine 50 (P-Ser 50), antiphosphoserine 62 (P-Ser 62), and anti-phosphoserine 73 (P-Ser 73) antibodies. The SCG10 protein and its phosphoforms migrate as multiple bands of $\sim 23-25 \mathrm{kDa}$. The smaller bands seen with P-Ser 50 and P-Ser 62 antibodies might correspond to degradation forms. The phospho-antibodies do not recognize unphosphorylated SCG10 produced in E. coli (lane 1), stathmin produced in E. coli (lane 2) or in baculovirus (lane 3), or stathmin in COS-7 cell extracts (lane 5), except that the P-Ser 50 antibody shows a very faint cross-reactivity. A parallel Western blot (bottom panel) with identical loading (except that only $0.5 \mu \mathrm{g}$ of $\mathrm{COS}-7$ cell extract was loaded on lane 4) was performed with nonpurified SCG10 antiserum, which recognizes both SCG10 and stathmin.

$1007 \pm 659(n=116 ; p<0.001$ by two-sample Wilcoxon test $)$. This reduction in SCG10 preceded alterations in the microtubule cytoskeleton (Fig. 5D,E, bottom panels), suggesting that the redistribution or degradation of SCG10 was an early response leading to growth cone pauses. There was no statistically significant difference in the mean area of the two groups of growth cones ( $p=0.32 ; t$ test). The untreated growth cones on L1 exhibited a mean area $\pm \mathrm{SD}$ of $84 \pm 23 \mu \mathrm{m}^{2}$, whereas growth cones on L1 treated with EphB and laminin peptides exhibited a mean area \pm $\mathrm{SD}$ of $81 \pm 25 \mu \mathrm{m}^{2}$.

Changes in protein levels similar to that seen with SCG10 were not found for the growth cone microtubule regulator MAP1B. In untreated growth cones on L1, MAP1B was distributed in a granular pattern in the central core of the growth cones co-extensive with microtubules (Fig. 5F). Unlike SCG10, no change in MAP1B distribution was seen in growth cones treated with L1, laminin, and EphB (Fig. 5G). The mean fluorescence value of MAP1B in untreated growth cones was $1454 \pm 753(n=103)$ (Fig. 6C), and in treated growth cones it was $1401 \pm 640(n=102$; $p>0.06$ by two-sample Wilcoxon test) (Fig. $6 D$ ). There was no statistical difference in the mean size of growth cones from the two groups (untreated: $80 \pm 23 \mu \mathrm{m}^{2}$; treated: $79 \pm 18 \mu \mathrm{m}^{2} ; p=$ 0.79 ; $t$ test. Overall, these results suggested a model in which growth cones exposed to L1, laminin, and EphB lost SCG10 microtubule destabilizing activity but retained unopposed stabiliz- 
ing activity. The resulting decrease in growth cone microtubule dynamics, with its known inhibitory effects on axon elongation (Tanaka et al., 1995; Rochlin et al., 1996; Challacombe et al., 1997), could then lead to growth cone pauses.

\section{SCG10 perturbation leads to growth cone pauses}

To determine whether the loss of SCG10 function in growth cones treated with L1, laminin, and EphB can indeed result in growth cone pauses, we introduced an anti-SCG10 function blocking mouse monoclonal antibody in retinal growth cones extending on L1. Anti-SCG10 mAb specifically recognizes SCG10 without cross-reactivity with other stathmin family members (Di Paolo et al., 1997). Its ability to block SCG10 microtubuledepolymerizing activity was measured using an in vitro assay of microtubule assembly as described by Riederer et al. (1997). Anti-SCG10 mAb effectively blocked the ability of SCG10 to inhibit microtubule polymerization (Fig. 7).

Anti-SCG10 mAb was introduced into retinal growth cones using a lipid-based intracellular protein delivery reagent (Zelphati et al., 2001) (Bioporter, Gene Therapy Systems). In control experiments, Bioporter effectively delivered labeled secondary antibodies, anti-SCG10 polyclonal antibody, and anti-microtubule antibody into living retinal growth cones extending on L1 (Fig. 8A, $B, D$ ). Moreover, anti-SCG10 and anti-microtubule antibodies delivered by Bioporter were capable of specific antigen binding (Fig. $8 A, B$ ). In control experiments, growth cones loaded with control secondary antibody $(n=33)$ displayed steady elongation, and none exhibited pause behavior (Fig. 8C,E, Table 3 ). In contrast, $37 \%$ of growth cones loaded with anti-SCG10 functionblocking $\mathrm{mAb}(n=30)$ exhibited pauses ( $p<0.001$; Fisher exact test), with filopodial activity indistinguishable from growth cone responding to the combination of L1, laminin, and EphB (Fig. 8 F, Table 3). Furthermore, an additional $37 \%$ of antiSCG10 mAb-treated growth cones compared with 3\% of control growth cones showed growth rates of $<20 \mu \mathrm{m} / \mathrm{hr}$ (Table 3 ). Growth cones exhibiting pauses in response to anti-SCG10 mAb had microtubule changes similar to those encountered in growth cones exposed to L1, laminin, and EphB (Fig. 8G). These results supported a mechanism in which a reduction in SCG10 destabilizing activity increased microtubule stability and disrupted axon elongation.

\section{Discussion}

To better understand the regulation of EphB function during axon pathfinding, we investigated whether retinal growth cone
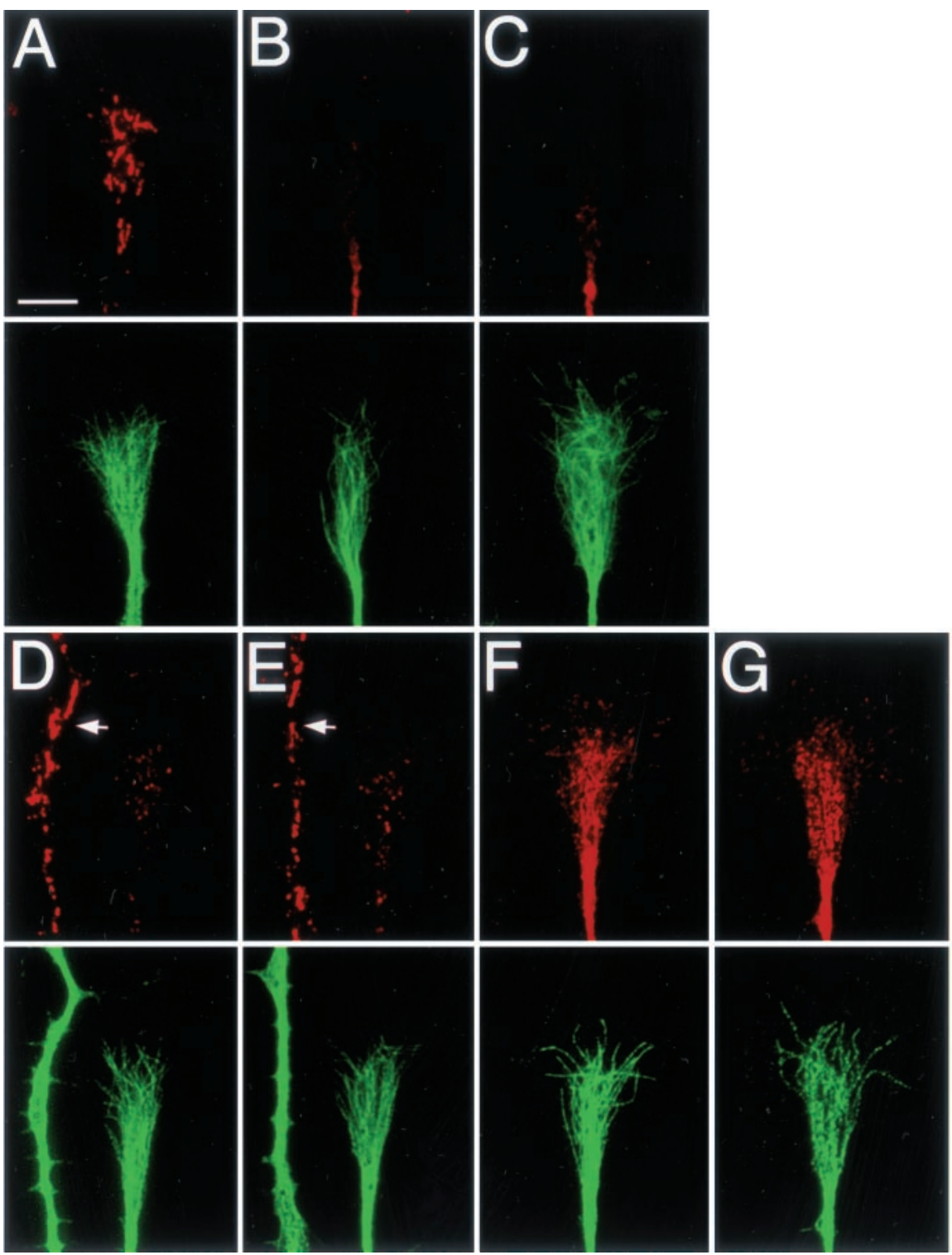

Figure 5. Regulators of growth cone microtubule assembly. The distribution of microtubules in each growth cone is shown in the bottom panel in green. Scale bars: $A-G,=5 \mu \mathrm{m} . A, S C G 10$ in normal growth cones on $L 1$ was present as punctate aggregates in the central domain (top), co-extensive with microtubules (bottom). $B$, Serine 62-phosphorylated SCG10 was normally present in the axon shaft but almost completely absent in growth cones. C, Growth cones exposed to L1, laminin, and EphB did not show an increase in SCG10 serine 62 phosphorylation. The microtubule array in this growth cone (bottom) was enlarged and disorganized, indicating that the characteristic pause behavior had occurred. D, Growth cones exposed to L1, laminin, and EphB showed decreased levels of SCG10 (detected using an antibody against SCG10 C-terminal peptide). SCG10 remained in the axon shaft on the left (arrow). Changes in SCG10 occurred before alterations in microtubules (bottom). E, Decreased levels of growth cone SCG10 (detected using antisera against SCG10 recombinant protein) after exposure to L1, laminin, and EphB. SCG10 remained in the axon shaft on the left (arrow). F, MAP1B was present in the central domain of normal growth cones extending on L1. G, Growth cones exposed to L1, laminin, and EphB showed no obvious changes in MAP1B distribution.

responsiveness to EphB proteins was influenced by co-impinging signals from other guidance molecules present in the retinal pathway, such as laminin and L1. Retinal growth cone response to the pairing of EphB with L1 or EphB with a combination of L1 and laminin was analyzed using time-lapse microscopy. We found that in contrast to growth cone collapse after exposure to EphB paired with laminin (Birgbauer et al., 2001), pairing with L1 rendered retinal axons insensitive to EphB. The combination of laminin and L1, however, restored the ability of EphB to influence retinal growth cones and elicited a novel pause behavior distinct from growth cone collapse. Paused growth cones main- 

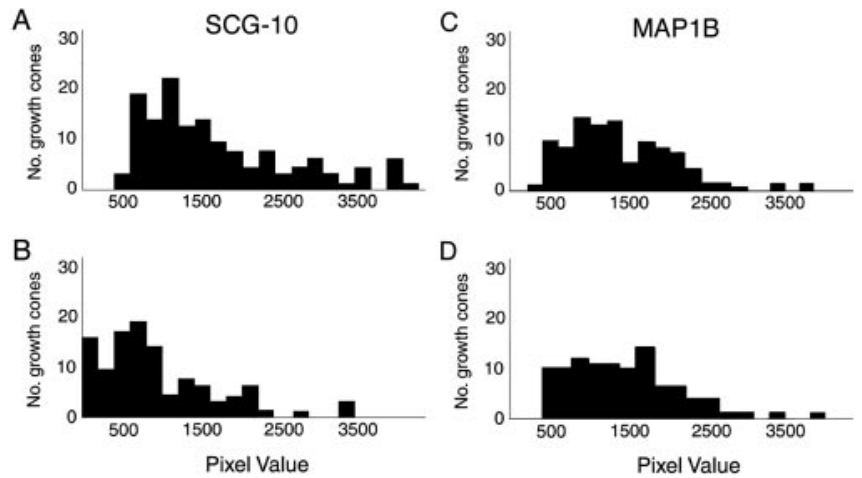

Figure 6. Quantitation of SCG10 and MAP1B levels in growth cones. A, SCG10 in retinal growth cones on L1. B, SCG10 in retinal growth cones on L1 treated with bath-applied EphB2-FC and laminin peptides. These two populations of growth cones showed a statistically significant difference in mean SCG10 levels in a two-sample Wilcoxon test (see Results for details). C, MAP1B in retinal growth cones on L1. D, MAP1B in retinal growth cones on L1 treated with bath-applied EphB2-Fc and laminin peptides. These two populations of growth cones did not show a statistically significant difference in mean MAP1B levels in a two-sample Wilcoxon test (see Results).

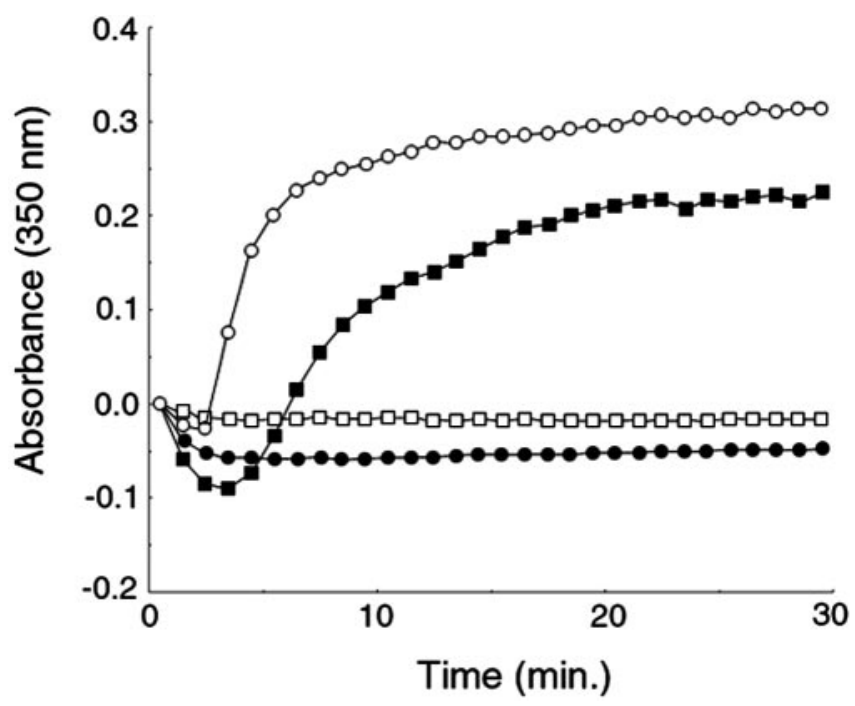

Figure 7. Anti-SCG10 mAb inhibition of SCG10-mediated microtubule disassembly: $\bigcirc$, assembly of tubulin subunits into microtubules; , SCG10 in the micromolar range completely blocked microtubule polymerization; $\boldsymbol{\square}$, the addition of equimolar amounts of anti-SCG10 mAb with SCG10 restored tubulin polymerization and microtubule formation to control levels (between 65 and $100 \%$ of control levels in 4 independent experiments); $\square$, addition of control lgG (purified mouse IgG from Sigma) to SCG10 had no effect on the ability of SCG10 to inhibit microtubule assembly. IgG or SCG10 mAb alone had no effect (data not shown).

tained a normal fan-like morphology, actin distribution, filopodial activity, and sensitivity to Rho-mediated collapse. They have, however, altered microtubule organization and a loss of SCG10, a growth cone protein known to inhibit microtubule assembly. SCG10 function blockade in growth cones elicited pauses and microtubule changes indistinguishable from those resulting after L1, laminin, and EphB protein exposure. Together these results provide insight into two aspects of EphB activity. One, the ability of EphB to inhibit retinal growth cones is dependent on the nature of co-impinging signals such that EphB inhibits growth cones that also receive laminin signals but does not affect growth cones receiving $\mathrm{L} 1$ input. Second, in addition to its ability to activate typical growth cone collapse, EphB, when operating in the context of both laminin and L1 signals, can trigger growth

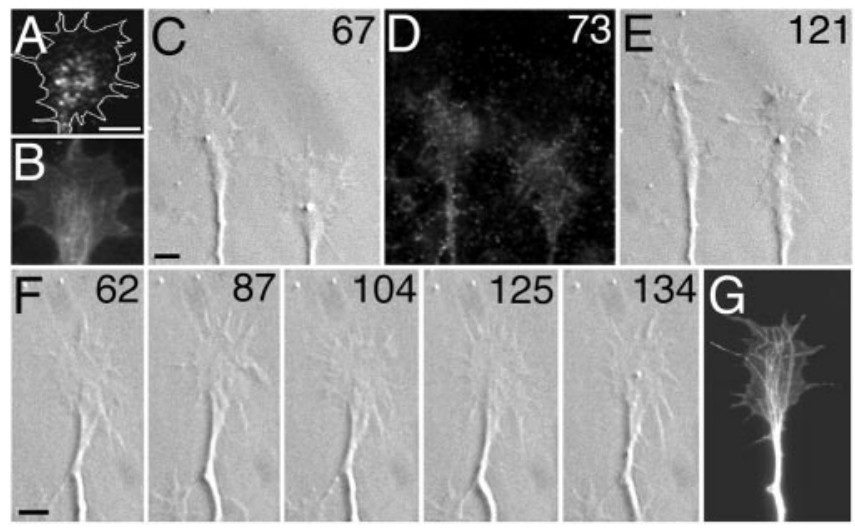

Figure 8. Perturbation of SCG10 function in growth cones. $A$, Growth cone on L1 loaded with anti-SCG10 polyclonal antibody using the lipid-based protein delivery reagent Bioporter. SCG10 was visualized with anti-rabbit secondary antibody and detected in its normal location in the central growth cone region. $B$, Growth cone on $\mathrm{L} 1$ loaded with anti-microtubule antibody conjugated with Alexafluor 488. C, Bright-field image of two growth cones $67 \mathrm{~min}$ after loading with Cy2 secondary antibody. Scale bars: $(-E, 5 \mu \mathrm{m}$. D, Fluorescence image of the same growth cone pair in $3 C$, confirming loading of secondary antibody. E, The same growth cones at $121 \mathrm{~min}$, indicating normal axon growth after control antibody loading. $F$, Time-lapse sequence of a growth cone loaded with anti-SCG10 function-blocking $\mathrm{mAb}$. The growth cone maintained filopodial and lamellapodial activity but has paused in its forward elongation. Time (in minutes) after application of anti-SCG10 mAb is indicated at top right. Scale bar, $5 \mu \mathrm{m}$. G, Appearance of tyrosinated microtubules in the growth cone shown in $F$.

Table 3. Embryonic retinal growth cone response to SCG10 function blockade

\begin{tabular}{llllll}
\hline & Number of & \multicolumn{5}{l}{ Response type (\%) } \\
\cline { 3 - 6 } & growth cones & Pause & $<20 \mu \mathrm{m} / \mathrm{hr}$ & $>20 \mu \mathrm{m} / \mathrm{hr}$ & $>40 \mu \mathrm{m} / \mathrm{hr}$ \\
\hline Anti-SCG10 mAb & 30 & 37 & 37 & 23 & 3 \\
Control Ab & 33 & 0 & 3 & 73 & 24
\end{tabular}

The number of pauses and the elongation rates of growth cones treated with anti-SCG10 $\mathrm{mAb}$ were compared with that in growth cones treated with a Cy2-donkey anti-rabbit control antibody. The number of anti-SCG10 mAbtreated versus control antibody-treated growth cones in each of the four response categories was significantly different $(p<0.001$; Fisher exact test).

cone microtubule changes to initiate an inhibitory pause behavior without resulting in actin-mediated growth cone collapse.

\section{Activation of growth cone pauses}

The difference in responsiveness to EphB when growth cones are extending on laminin versus L1 or the combination of laminin and $\mathrm{L} 1$ is unlikely caused by suboptimal doses of EphB proteins. The concentration of EphB-Fc used in the present study is the same as that used previously to study the responses of identical growth cones extending on laminin to EphB (Birgbauer et al., 2001). Even if pausing is on the same continuum of growth cone responses as collapse, and that pausing leads to collapse at exposure to higher EphB levels, the existence of the "paused" state provides insight into the mechanisms of growth cone inhibition. Unlike collapsed growth cones, paused growth cones, with their open morphology, offer an opportunity to characterize the growth cone cytoskeleton during inhibitory responses to guidance molecules.

\section{Involvement of microtubules in growth cone inhibition}

Axon pathfinding requires precise control of the growth cone actin and microtubule cytoskeleton. Although inhibitory axon guidance molecules are known to trigger changes in actin via Rho GTPases, it is not clear how inhibitory signals are conveyed to growth cone microtubules. Results here suggest that there is communication from inhibitory guidance receptors to regulators of 
microtubule assembly such as SCG10. A number of studies have previously demonstrated a link between microtubule stability and in vitro growth cone extension and pathfinding (Tanaka et al., 1995; Challacombe et al., 1997; Buck and Zheng, 2002; Zhou et al., 2002). Our results here explore the physiological signals that may regulate growth cone microtubules and suggest a link between stimulation by known inhibitory axon guidance molecules and SCG10-mediated regulation of growth cone microtubule assembly. Furthermore, they demonstrate that under the influence of certain axon guidance molecules, microtubule changes can occur without gross actin rearrangement, loss of sensitivity to Rho GTPase-mediated disassembly, or elimination of filopodial activity.

\section{Mechanisms of growth cone pauses}

Although actin-mediated collapse was not observed, our results do not rule out the possibility that the signaling pathways leading to growth cone pauses feed through actin. Although growth cone microtubules are segregated, to a large extent, from the actin-rich peripheral domain, entry by individual microtubules into the peripheral region is known to occur (Gordon-Weeks, 1991; Schaefer et al., 2002; Zhou et al., 2002) (Table 2). Actin has been shown to limit the entry of dynamic microtubules into the peripheral growth cone region (Forscher and Smith, 1988; Suter and Forscher, 2000; Zhou et al., 2002), and recent work suggests that it may be the phenomenon of actin retrograde flow that prevents encroachment by microtubules (Zhou et al., 2002). Thus, during the growth cone pauses observed in the present study, a loss of retrograde actin flow may underlie the increased number of microtubules invading the growth cone periphery and filopodia. If so, then changes in actin retrograde flow must occur at levels sufficient to allow microtubule invasion but not sufficient to interfere with the maintenance of filopodial activity during growth cone pauses.

In addition to the possible involvement of actin, several findings support the notion that after L1, laminin, and EphB exposure, additional mechanisms are at work in the central domain of the growth cone to bring about growth cone pauses. First, SCG10, a known growth cone inhibitor of microtubule assembly (Riederer et al., 1997), was lost from its position in the central domain where it normally roughly colocalized with the dynamic pool of microtubules. Second, alteration in SCG10 levels did not appear to result secondarily from changes affecting growth cone microtubules in general, because MAP1B, a microtubule stabilizer also associated with the dynamic pool of microtubules, was unaffected. Third, the finding that SCG10 function blockade resulted in similar growth cone pause behaviors was consistent with the idea that L1, laminin, and EphB induced pauses by altering SCG10 function. Although it has been shown that focal application of low-dose taxol causes growth cone turning toward the side in which microtubules have been stabilized (Buck and Zheng, 2002), substantial evidence indicates that a spatially generalized loss of dynamic microtubules throughout the growth cone leads to cessation of axon extension (Tanaka et al., 1995; Gallo, 1998). This disruption of axon extension is remarkably similar to the growth cone pauses described in the present study. Thus a plausible mechanism of L1, laminin, and EphB activity involves a decrease in SCG10 activity, which alters the balance in favor of increased microtubule stability to give rise to inhibitory growth cone pauses. Such a mechanism predicts that retinal growth cone microtubule dynamics show a net increase in polymerization after exposure to specific combinations of axon guidance mole- cules. The direct analysis of microtubule dynamics in such growth cones would allow a test of this hypothesis.

\section{$\mathrm{L} 1$ and responsiveness to EphB}

A recent study reported that retinal axons in the frog optic tectum respond to EphB as a positive or attractive signal and grow toward midbrain regions expressing this molecule (Mann et al., 2002). This attraction response is in contrast to the finding in mouse that retinal axons during pathfinding to the optic disc appear to respond to $\mathrm{EphB}$ as an inhibitory guidance molecule (Birgbauer et al., 2000, 2001). One explanation to tie together both findings is that retinal axons may switch from being inhibited by EphB during pathfinding in the retina to being attracted by EphB during topographic mapping in midbrain targets. Response switching between growth cone attraction and repulsion has been observed in vitro and appears to involve modulation of cAMP levels (Song and Poo, 1999). Given the ability of L1 to cause growth cones to alter their response to Sema3A from inhibition to attraction (Castellani et al., 2000), we examined whether L1 could act in a similar manner for retinal growth cones responding to EphB. The results, however, showed that L1 did not have the ability to alter retinal growth cone responsiveness to EphB from inhibition to attraction, but instead generally made retinal growth cones insensitive to this guidance molecule. Although it is possible that we were unable to detect an attractive turning response of E14 mouse retinal axons to EphB because of technical issues with micropipette assays, the same micropipette assays in our hands have elicited attractive turning responses in postnatal mouse retinal axons to axon guidance molecules (X. Liu, D. Sretavan, unpublished data). On the basis of these results, the possibility that $\mathrm{L} 1$ does not have a universal ability to cause response switching should be considered. This is consistent with a recent finding that retinal growth cone inhibition by Sema5A also appears not to be altered by the presence of L1 signaling (Oster et al., 2003). Currently, the switch in responsiveness to EphB between the retina and the tectum requires further study. One set of candidates that may be involved is other axon guidance molecules in the optic tectum.

\section{Growth cone pauses during pathfinding in vivo}

Studies using time-lapse microscopy to analyze growth cone behavior at complex pathfinding regions such as the optic chiasm have noted episodes during which retinal axons stop elongation but continue filopodial exploratory activity (Sretavan and Reichardt, 1993; Godement et al., 1994), exhibiting a behavior that resembles the growth cone pauses described here. Although growth cone collapse is generally considered a standard inhibitory response, full collapse by itself will not lead to effective pathfinding. Instead, it is thought that collapse occurs in an attenuated form in vivo or that inhibitory molecules are asymmetrically presented to one side of the growth cone to cause turning (Fan and Raper, 1995). Similar to collapse, attenuated forms of the pause behavior could take place in vivo, resulting in slowed axon elongation but maintenance of exploratory behavior. In addition, asymmetric presentation of guidance molecules that result in pausing on one side of the growth cone may also lead to meaningful pathfinding behavior.

\section{Implications for in vivo pathfinding}

One potential implication of our results is that EphB function in vivo is regulated by the ratio of $\mathrm{L} 1$ and laminin in the environment. Differential regulation by $\mathrm{L} 1$ and laminin may help explain why axon pathfinding errors in the retinas of EphB2, B3 double 
null mutant mice are localized to a region near the optic disc (Birgbauer et al., 2000). Although retinal axons express L1 throughout their course in the retina during exit into the optic nerve, they are thought to encounter laminin only in the immediate region of the optic disc (Hopker et al., 1999). Thus, it is only near the optic disc that retinal axons find themselves exposed to co-impinging laminin and L1 signals and can respond to EphB present in this region. The resulting pause response would then ensure that retinal axons do not overshoot this exit point. The continued filopodial activity, however, would also allow retinal growth cones to detect additional guidance molecules at the optic disc such as netrin-1, which has been shown to be necessary for retinal axon exit through the optic disc into the optic nerve (Deiner et al., 1997). Such a scenario is consistent with findings showing that retinal growth cones during pathfinding at the developing optic nerve head maintain prominent filopodia and a complex morphology (Holt, 1989). According to this model of retinal growth cone pathfinding, in addition to actin-mediated collapse, the nervous system has the additional option of using microtubule-dependent pauses. Such pauses accompanied by continued filopodial activity could serve as a mechanism to allow growth cones to respond to inhibitory axon guidance molecules as stop signals but remain responsive to additional cues governing their next pathfinding task in the establishment of neuronal connectivity.

\section{References}

Antonsson B, Montessuit S, Di Paolo G, Lutjens R, Grenningloh G (1997) Expression, purification, and characterization of a highly soluble $\mathrm{N}$-terminal-truncated form of the neuron-specific membrane-associated phosphoprotein SCG10. Protein Expr Purif 9:295-300.

Antonsson B, Kassel DB, Di Paolo G, Lutjens R, Riederer BM, Grenningloh G (1998) Identification of in vitro phosphorylation sites in the growth cone protein SCG10. Effect Of phosphorylation site mutants on microtubuledestabilizing activity. J Biol Chem 273:8439-8446.

Antonsson B, Kassel DB, Ruchti E, Grenningloh G (2001) Differences in phosphorylation of human and chicken stathmin by MAP kinase. J Cell Biochem 80:346-352.

Bartsch U, Kirchhoff F, Schachner M (1989) Immunohistochemical localization of the adhesion molecules L1, N-CAM, and MAG in the developing and adult optic nerve of mice. J Comp Neurol 284:451-462.

Birgbauer E, Cowan CA, Sretavan DW, Henkemeyer M (2000) Kinase independent function of EphB receptors in retinal axon pathfinding to the optic disc from dorsal but not ventral retina. Development 127:1231-1241.

Birgbauer E, Oster SF, Severin CG, Sretavan DW (2001) Retinal axon growth cones respond to EphB extracellular domains as inhibitory axon guidance cues. Development 128:3041-3048.

Buck KB, Zheng JQ (2002) Growth cone turning induced by direct local modification of microtubule dynamics. J Neurosci 22:9358-9367.

Cassimeris L (2002) The oncoprotein 18/stathmin family of microtubule destabilizers. Curr Opin Cell Biol 14:18-24.

Castellani V, Chedotal A, Schachner M, Faivre-Sarrailh C, Rougon G (2000) Analysis of the L1-deficient mouse phenotype reveals cross-talk between Sema3A and L1 signaling pathways in axonal guidance. Neuron 27:237-249.

Challacombe JF, Snow DM, Letourneau PC (1997) Dynamic microtubule ends are required for growth cone turning to avoid an inhibitory guidance cue. J Neurosci 17:3085-3095.

Cowan CA, Henkemeyer M (2001) The SH2/SH3 adaptor Grb4 transduces B-ephrin reverse signals. Nature 413:174-179.

Deiner MS, Kennedy TE, Fazeli A, Serafini T, Tessier-Lavigne M, Sretavan DW (1997) Netrin-1 and DCC mediate axon guidance locally at the optic disc: loss of function leads to optic nerve hypoplasia. Neuron 19:575-589.

Di Paolo G, Lutjens R, Osen-Sand A, Sobel A, Catsicas S, Grenningloh G (1997) Differential distribution of stathmin and SCG10 in developing neurons in culture. J Neurosci Res 50:1000-1009.

Ethell IM, Irie F, Kalo MS, Couchman JR, Pasquale EB, Yamaguchi Y (2001)
EphB/syndecan-2 signaling in dendritic spine morphogenesis. Neuron 31:1001-1013.

Fan J, Raper JA (1995) Localized collapsing cues can steer growth cones without inducing their full collapse. Neuron 14:263-274.

Forscher P, Smith SJ (1988) Actions of cytochalasins on the organization of actin filaments and microtubules in a neuronal growth cone. J Cell Biol 107:1505-1516.

Gallo G (1998) Involvement of microtubules in the regulation of growth cone morphologic remodeling. J Neurobiol 35:121-140.

Godement P, Wang LC, Mason CA (1994) Retinal axon divergence in the optic chiasm: dynamics of growth cone behavior at the midline. J Neurosci 14:7024-7039.

Gordon-Weeks PR (1991) Evidence for microtubule capture by filopodial actin filaments in growth cones. NeuroReport 2:573-576.

Gordon-Weeks PR, Fischer I (2000) MAP1B expression and microtubule stability in growing and regenerating axons. Microsc Res Tech 48:63-74.

Hall H, Deutzmann R, Timpl R, Vaughn L, Schmitz B, Schachner M (1997) HNK-1 carbohydrate-mediated cell adhesion to laminin-1 is different from heparin-mediated and sulfatide-mediated cell adhesion. Eur J Biochem 246:233-242.

Hankin MH, Lagenaur CF (1994) Cell adhesion molecules in the early developing mouse retina: retinal neurons show preferential outgrowth in vitro on L1 but not N-CAM. J Neurobiol 25:472-487.

Henkemeyer M, Orioli D, Henderson JT, Saxton TM, Roder J, Pawson T, Klein R (1996) Nuk controls pathfinding of commissural axons in the mammalian central nervous system. Cell 86:35-46.

Hindges R, McLaughlin T, Genoud N, Henkemeyer M, O’Leary D (2002) $\mathrm{EphB}$ forward signaling controls directional branch extension and arborization required for dorsal-ventral retinotopic mapping. Neuron 35:475-487.

Holt CE (1989) A single-cell analysis of early retinal ganglion cell differentiation in Xenopus: from soma to axon tip. J Neurosci 9:3123-3145.

Hopker VH, Shewan D, Tessier-Lavigne M, Poo M, Holt C (1999) Growthcone attraction to netrin-1 is converted to repulsion by laminin-1. Nature 401:69-73.

Kozma R, Sarner S, Ahmed S, Lim L (1997) Rho family GTPases and neuronal growth cone remodeling: relationship between increased complexity induced by $\mathrm{Cdc} 42 \mathrm{Hs}$, Racl, and acetylcholine and collapse induced by RhoA and lysophosphatidic acid. Mol Cell Biol 17:1201-1211.

Kranenburg O, Poland M, van Horck FP, Drechsel D, Hall A, Moolenaar WH (1999) Activation of RhoA by lysophosphatidic acid and Galpha12/13 subunits in neuronal cells: induction of neurite retraction. Mol Biol Cell 10:1851-1857.

Krendel M, Zenke FT, Bokoch GM (2002) Nucleotide exchange factor GEF-H1 mediates cross-talk between microtubules and the actin cytoskeleton. Nat Cell Biol 4:294-301.

Lee S, Kolodziej PA (2002) Short stop provides an essential link between F-actin and microtubules during axon extension. Development 129:1195-1204.

Liesi P, Silver J (1988) Is astrocyte laminin involved in axon guidance in the mammalian CNS? Dev Biol 130:774-785.

Lu Q, Sun EE, Klein RS, Flanagan JG (2001) Ephrin-B reverse signaling is mediated by a novel PDZ-RGS protein and selectively inhibits $G$ proteincoupled chemoattraction. Cell 105:69-79.

Luo L (2000) Rho GTPases in neuronal morphogenesis. Nat Rev Neurosci $1: 173-180$

Lyckman AW, Moya KL, Confaloni A, Jhaveri S (2000) Early postnatal expression of L1 by retinal fibers in the optic tract and synaptic targets of the Syrian hamster. J Comp Neurol 423:40-51.

Mann F, Ray S, Harris W, Holt C (2002) Topographic mapping in dorsoventral axis of the Xenopus retinotectal system Depends on signaling through Ephrin-B ligands. Neuron 35:461-473.

Morissette N, Carbonetto S (1995) Laminin $\alpha 2$ chain (M chain) is found within the pathway of avian and murine retinal projections. J Neurosci 15:8067-8082.

Nakagawa S, Brennan C, Johnson KG, Shewan D, Harris WA, Holt CE (2000) Ephrin-B regulates the ipsilateral routing of retinal axons at the optic chiasm. Neuron 25:599-610.

Nakazawa T, Nakano I, Furuyama T, Morii H, Tamai M, Mori N (2000) The SCG10-related gene family in the developing rat retina: persistent expression of SCLIP and stathmin in mature ganglion cell layer. Brain Res 861:399-407. 
Oster SF, Bodeker MO, He F, Sretavan DW (2003) Invariant Sema5A inhibition serves an ensheathing function during optic nerve development. Development 130:775-784.

Ozon S, Maucuer A, Sobel A (1997) The stathmin family-molecular and biological characterization of novel mammalian proteins expressed in the nervous system. Eur J Biochem 248:794-806.

Ozon S, Byk T, Sobel A (1998) SCLIP: a novel SCG10-like protein of the stathmin family expressed in the nervous system. J Neurochem 70:2386-2396.

Pellier-Monnin V, Astic L, Bichet S, Riederer BM, Grenningloh G (2001) Expression of SCG10 and stathmin proteins in the rat olfactory system during development and axonal regeneration. J Comp Neurol 433:239-254.

Riederer BM, Pellier V, Antonsson B, Di Paolo G, Stimpson SA, Lutjens R, Catsicas S, Grenningloh G (1997) Regulation of microtubule dynamics by the neuronal growth-associated protein SCG10. Proc Natl Acad Sci USA 94:741-745.

Rochlin MW, Wickline KM, Bridgman PC (1996) Microtubule stability decreases axon elongation but not axoplasm production. J Neurosci 16:3236-3246

Schaefer AW, Kabir N, Forscher P (2002) Filopodia and actin arcs guide the assembly and transport of two populations of microtubules with unique dynamic parameters in neuronal growth cones. J Cell Biol 158:139-152.

Song HJ, Poo MM (1999) Signal transduction underlying growth cone guidance by diffusible factors. Curr Opin Neurobiol 9:355-363.
Sretavan DW, Reichardt LF (1993) Time-lapse video analysis of retinal ganglion cell axon pathfinding at the mammalian optic chiasm: growth cone guidance using intrinsic chiasm cues. Neuron 10:761-777.

Stein E, Tessier-Lavigne M (2001) Hierarchical organization of guidance receptors: silencing of netrin attraction by slit through a Robo/DCC receptor complex. Science 291:1928-1938.

Suter DM, Forscher P (2000) Substrate-cytoskeletal coupling as a mechanism for the regulation of growth cone motility and guidance. J Neurobiol 44:97-113

Tanaka E, Ho T, Kirschner MW (1995) The role of microtubule dynamics in growth cone motility and axonal growth. J Cell Biol 128:139-155.

Walczak CE (2000) Microtubule dynamics and tubulin interacting proteins. Curr Opin Cell Biol 12:52-56.

Xu Q, Mellitzer G, Robinson V, Wilkinson DG (1999) In vivo cell sorting in complementary segmental domains mediated by Eph receptors and ephrins. Nature 399:267-271.

Zelphati O, Wang Y, Kitada S, Reed JC, Felgner PL, Corbeil J (2001) Intracellular delivery of proteins with a new lipid-mediated delivery system. J Biol Chem 276:35103-35110.

Zhou F-Q, Waterman-Storer CM, Cohan CS (2002) Focal loss of actin bundles causes microtubule redistribution and growth cone turning. J Cell Biol 157:839-849. 